\title{
Persistent Ascites after Orthotopic Liver Transplantation: Analysis of Predictive Factors
}

\section{Marcos Mucenic*, Ajacio B. M. Brandao, Claudio A. Marroni, Alfeu M. Fleck-Junior, Maria L. Zanotelli and Guido P. C. Cantisani}

Liver Transplantation Group, Irmandade Santa Casa de Misericórdia de Porto Alegre, Porto Alegre, RS, Brazil

${ }^{*}$ Corresponding author: Marcos Mucenic, Liver Transplantation Group, Avenida Bage 1006/301, 90460-080, Porto Alegre, Brazil, Tel: 55-51-992275699; E-mail: mmucenic@gmail.com

Received date: September 26, 2018; Accepted date: November 09, 2018; Published date: November 12, 2018

Copyright: (c) 2018 Mucenic M, et al. This is an open-access article distributed under the terms of the Creative Commons Attribution License, which permits unrestricted use, distribution, and reproduction in any medium, provided the original author and source are credited.

\begin{abstract}
Objective: Long-term persistence of ascites after orthotopic liver transplant can impact significantly on postoperative morbidity. Previous studies disclosed varied results in regard to prevalence, risk factors, ascitic fluid analysis and prognosis. The objective of the present study was to ascertain prevalence and risk factors in order to have a better understanding of this complication.

Methods: All orthotopic liver transplantations performed for three consecutive years were considered for inclusion. The outcome was defined as ascites that was evident on clinical examination and/or required the use of diuretics for more than 90 days after surgery.

Results: The main indications for transplant were decompensated cirrhosis and hepatocellular carcinoma. Ascites persisted in $19(13.67 \%)$ out of 139 cases. Predictive factors were portosystemic encephalopathy, portal vein thrombosis, splenomegaly, creatinine level and volume of ascites drained during surgery. On multiple regression analysis, only the amount of ascites drained during transplantation $(5.05 \mathrm{~L} \times 1.58 \mathrm{~L} ; \mathrm{p}<0.008)$ and creatinine levels less than 12 hours before transplantation $(2.39 \mathrm{mg} / \mathrm{dL} \times 1.22 \mathrm{mg} / \mathrm{dL} ; \mathrm{p}=0.018)$ remained significantly related to ascites persistence. All biochemical analysis revealed increased serum-ascites albumin gradient. Death in the first year was similar in patients with or without ascites persistence $(5.6 \times 4.3 \%)$
\end{abstract}

Conclusion: This study evaluated multiple potential risk factors that could contribute to long-term persistence of ascites after liver transplantation. Loss of renal function and greater volume of ascites were significantly related to persistent ascites, which was a transudate with increased serum-ascites albumin gradient. Persistent ascites was not associated with increased mortality.

Keywords Cirrhosis; Portal hypertension; Outcome ascites; Liver transplantation

Abbreviations ACR: Acute cellular rejection; DDLT: Deceased donor liver transplantation; LDLT: Living donor liver transplantation; MELD: Model for end-stage liver disease; TIPS: Transjugular intrahepatic portosystemic shunt.

\section{Introduction}

Ascites persists in a small percentage of patients after deceased donor liver transplantation (DDLT), without graft dysfunction or surgical complications to explain it in most of the cases [1]. Some authors have found it to be associated to bacterial and fungal infections and to increased mortality [2,3]. Transjugular intrahepatic portosystemic shunt (TIPS) was largely ineffective [4,5]. Although the mechanical component of portal hypertension (the cirrhotic liver) reverts after DDLT, post-operatory ascites could be explained by the persistence of hyperdynamic circulation and splanchnic vasodilatation. Decreased liver complacency caused by common liver disorders such as acute cellular rejection (ACR) could also play a role [6-9]. Retrospective studies disclosed varied results in regard to prevalence, risk factors, ascitic fluid analysis and prognosis. By means of a thorough analysis of potential predictive variables, there could be a better understanding of this ill-defined complication. The objective of the present study is to ascertain prevalence and risk factors for the persistence of ascites after DDLT.

\section{Patients and Methods}

The outcome was defined as ascites that was evident on clinical exam and/or required the use of diuretics for more than 90 days after the DDLT. Data from medical charts was obtained retrospectively. Variables included for analysis were demographic (gender, race, age, blood type), clinical in regard to pre-transplant history (etiology of liver disease, presence of hepatocellular carcinoma, complications of cirrhosis), Model for End-Stage Liver Disease (MELD) and creatinine values, abdominal imaging findings (splenomegaly, spleen size, portal vein diameter, ascites, portal vein thrombosis) and the more frequent echocardiographic signs (diastolic dysfunction and left atrial overload). Variables related to surgery were warm and cold ischemia time and volume of ascites drained transoperatively. Donor-related variables were gender, race, age, blood type, vasopressor use and alcohol use. Episodes of biopsy-proven ACR were categorized as indeterminate, mild, moderate or severe according to Banff criteria [10].

Superior abdominal ultrasonographic follow-up with colored Doppler effect was undertaken thrice in the first week after DDLT, 
twice in the second week and once a week until hospital discharge. Postoperative portal vein thrombosis or outflow block were ruled out by means of these routine evaluations.

Immunosuppression began with $250 \mathrm{mg}$ of methylprednisolone, reduced daily, then changed to prednisone $20 \mathrm{mg}$ after the first 4 or 5 days after DDLT. This was associated with calcineurin inhibitors (tacrolimus or cyclosporine) that were initiated within 24 hours of the transplantation procedure.

All liver transplantations performed for three consecutive years were considered for inclusion. All patients received whole-graft deceased donor livers and were operated on using the piggyback technique. Exclusion criteria were: (1) death or re-transplantation before 90 days and (2) patients that did not have cirrhosis before the first transplantation. Cases of re-transplantation and combined liverkidney transplantation were accepted for inclusion and submitted to subgroup analysis.

For hepatocellular carcinoma, the priority rules were applied as determined by the national government agency: an arbitrary MELD value of 20 points was given initially, which increased to 24 points after 3 months and 29 points after 6 months on the waiting list. Only cases within the Milan criteria were listed: nodules equal or greater than 2 $\mathrm{cm}$ in diameter were given priority and patients could have up to one nodule measuring no more than $5 \mathrm{~cm}$ in diameter or up to three nodules measuring no more than $3 \mathrm{~cm}$ in diameter. For statistical analysis, only the calculated (not the arbitrary) MELD was used.
Statistical analysis was applied according to the characteristics of each variable, on an individual basis. For $2 \times 2$ comparisons, Pearson's Chi-Square was used. If any of the expected cells had an expected value less than 5, Fisher's Exact Test was applied. When comparing continuous variables, equality of variances was verified with Levene's Test. Student's $\mathrm{T}$ test was used for continuous variables with equal variances. Otherwise Welch's T-test for unequal variances was applied. A multinomial Logistic Regression was used for all variables that were significantly related to ascites persistence. A significance value (twosided) of 0.05 was accepted. The study was approved by the local Ethics committee.

\section{Results}

A total of 139 cases of DDLT were included in the study. Main sample characteristics are described in Table 1. The median age of receptors was 55 (14-73) years and the median age of donors was 47 (12-82) years. The pre-transplantation median calculated MELD value was 20 (8-42). The median cold ischemia time was 507 (138-914) minutes and the median warm ischemia time was 60 (1-262) minutes. The indications for transplant were decompensated cirrhosis (48.9\%), hepatocellular carcinoma (46.8\%), posttransplant cholestasis (3.6\%) and hepatopulmonary syndrome $(0.7 \%)$.

\begin{tabular}{|c|c|c|c|c|}
\hline Variables & \multicolumn{4}{|c|}{ Characteristics (\%) ${ }^{1}$} \\
\hline \multicolumn{5}{|l|}{ Receptors } \\
\hline Blood Type & A (41.4) & $\mathrm{B}(10)$ & $\mathrm{AB}(1.4)$ & $\mathrm{O}(46.4)$ \\
\hline Gender & Female(25.0) & & & \\
\hline \multirow[t]{2}{*}{ Race } & White(77.2) & Mulatto(11.0) & Afro-descendent (11.8) & \\
\hline & Hepatitis C: 35.7 & \multicolumn{2}{|c|}{ Hepatitis C and alcohol: 27.9} & \\
\hline Cause of cirrhosis & Alcohol: 8.6 & Hepatitis B: 6.4 & Others: 21.42 & \\
\hline Combined liver-kidney & Yes (5.8) & No (94.2) & & \\
\hline Re-transplantation & Yes (4.4) & No (95.6) & & \\
\hline \multicolumn{5}{|l|}{ Donors } \\
\hline Gender & Female (40.9) & Male (59.1) & & \\
\hline Race & White (85.7) & Mulatto (12.6) & Afro-descendent (1.7) & \\
\hline
\end{tabular}

Table 1: Sample characteristics.

Ascites persisted after 90 days in 19 (13.7\%) cases. On individual cross-tabulations, variables that increased the risk for persistent ascites were clinical (history of at least one episode of portosystemic encephalopathy or spontaneous bacterial peritonitis), ultrasonographic (ascites, portal vein thrombosis or larger spleen size on previous abdominal ultrasound exam), laboratorial (greater serum creatinine level, collected less than 12 hours before transplantation) and surgical (larger volume of ascites drained during surgery). These and other tested variables are shown on Tables 2 and 3. On multiple regression analysis, only the amount of ascites drained during surgery $(\mathrm{p}<0.001)$ and creatinine levels $(\mathrm{p}=0.018)$ remained significantly related to persistence after 90 days (Table 4).

Biopsy-proven ACR was detected in 43 (30.9\%) cases. Twenty-five cases were defined as mild, 12 as moderate and 1 as severe. Persistent ascites was not found to be more common in patients with ACR $(15.6 \% \times 12.1 \% ; \mathrm{p}=0.57)$. Ascites was present in 5 patients with mild and in 2 patients with moderate ACR. There were no cases of portal vein thrombosis or outflow block after DDLT. 
Citation: Mucenic M, Brandao ABM, Marroni CA, Fleck-Junior AM, Zanotelli ML, et al. (2018) Persistent Ascites after Orthotopic Liver Transplantation: Analysis of Predictive Factors. J Liver 7: 232. doi:10.4172/2167-0889.1000232

Page 3 of 4

\begin{tabular}{|c|c|c|c|c|c|}
\hline \multirow[t]{2}{*}{ Variables } & \multicolumn{5}{|c|}{ Post-transplantation Ascites ${ }^{1}$} \\
\hline & \multicolumn{2}{|c|}{ Present (\%) } & \multicolumn{2}{|c|}{ Absent (\%) } & $\mathrm{p}$ value \\
\hline \multicolumn{6}{|l|}{ Clinical History } \\
\hline Ascites & \multicolumn{2}{|l|}{16.5} & \multicolumn{2}{|l|}{5.2} & 0.0722 \\
\hline $\begin{array}{l}\text { Spontaneous bacterial } \\
\text { peritonitis }\end{array}$ & \multicolumn{2}{|l|}{28} & \multicolumn{2}{|l|}{10.3} & 0.0463 \\
\hline Upper digestive hemorrhage & \multicolumn{2}{|l|}{10} & \multicolumn{2}{|l|}{14.9} & 0.4472 \\
\hline Portosystemic encephalopathy & \multicolumn{2}{|l|}{21.6} & \multicolumn{2}{|l|}{8.3} & 0.0362 \\
\hline Hepatorenal syndrome & \multicolumn{2}{|l|}{28.6} & \multicolumn{2}{|l|}{12.7} & 0.2443 \\
\hline Combined liver-kidney & \multicolumn{2}{|l|}{37.5} & \multicolumn{2}{|l|}{12} & 0.0763 \\
\hline Retransplantation & \multicolumn{2}{|l|}{0} & \multicolumn{2}{|l|}{14.4} & 1.0003 \\
\hline \multicolumn{6}{|l|}{ Abdominal ultrasound } \\
\hline Ascites & 22.1 & \multicolumn{2}{|l|}{3.3} & \multicolumn{2}{|c|}{0.0022} \\
\hline Portal vein thrombosis & 26.7 & \multicolumn{2}{|l|}{9} & \multicolumn{2}{|c|}{0.0263} \\
\hline \multicolumn{6}{|l|}{ Echocardiographic findings } \\
\hline Diastolic disfunction & 14.3 & \multicolumn{2}{|l|}{11.3} & \multicolumn{2}{|c|}{0.6282} \\
\hline Left atrial overload & 15.2 & \multicolumn{2}{|l|}{10.5} & \multicolumn{2}{|c|}{0.4442} \\
\hline
\end{tabular}

Table 2: Influence of dichotomous variables on ascites persistence after liver transplantation.

\begin{tabular}{|c|c|c|c|}
\hline \multirow[t]{2}{*}{ Variables } & $\begin{array}{l}\text { Persistence of Post- } \\
\text { transplantation } \\
\text { Ascites }\end{array}$ & & \multirow[t]{2}{*}{$p$ value } \\
\hline & Yes (\%) & No $(\%)$ & \\
\hline MELD & $21.9(19.9-22.3)$ & $21.1(19.5-24.4)$ & 0.593 \\
\hline Creatinin 2 (mg/dL) & $2.39(1.42-3.36)$ & $1.22(0.97-1.49)$ & 0.0244 \\
\hline \multicolumn{4}{|l|}{ Ultrasound findings } \\
\hline $\begin{array}{l}\text { Portal vein diameter } \\
\text { (cm) }\end{array}$ & $12.8(10.4-15.1)$ & $13.1(12.5-13.8)$ & 0.703 \\
\hline Spleen size (cm) & $17.0(15.5-18.5)$ & $16.1(15.5-16.7)$ & 0.233 \\
\hline \multicolumn{4}{|l|}{ Donors } \\
\hline Age (years) & $43.5(34.8-52.2)$ & $44.4(41.2-47.5)$ & 0.843 \\
\hline \multicolumn{4}{|l|}{ Surgery } \\
\hline $\begin{array}{l}\text { Cold ischemia time } \\
(\min )\end{array}$ & $546.7(477.4-616.0)$ & $497.1(463.4-530.1)$ & 0.263 \\
\hline $\begin{array}{l}\text { Warm ischemia time } \\
\text { (min) }\end{array}$ & $63.0(56.2-69.8)$ & $67.3(62.1-72.5)$ & 0.543 \\
\hline $\begin{array}{l}\text { Volume of ascites } \\
\text { drained (L) }\end{array}$ & $5.05(2.65-7.46)$ & $1.58(1.07-2.10)$ & $<0.0084$ \\
\hline
\end{tabular}

Table 3: Influence of continuous variables on ascites persistence after liver transplantation.

\begin{tabular}{|l|l|}
\hline Variables & Significance level \\
\hline Previous encephalopathy or peritonitis & 0.281 \\
\hline Portal vein thrombosis & 0.431 \\
\hline Creatinine & 0.018 \\
\hline Volume of ascites drained (mililiters) & $<0.001$ \\
\hline $\begin{array}{l}{ }^{1} \text { History of ascites and ascites on ultrasound were not included in the analysis, } \\
\text { in order not to include redundant variables. }\end{array}$ \\
\hline
\end{tabular}

Table 4: Multinomial Logistic Regression Analysis ${ }^{1}$.

Abdominal paracentesis were undertaken in 9 of the 19 cases of ascites. All biochemical analyses revealed increased serum-ascites albumin gradient. Two cytological analyses revealed neutrascites suggestive of infection and were treated as such. There were no cases of chylous ascites. Death in the first year of post-operatory (from 90 to 365 days of surgery) was similar in patients with or without ascites persistence $(5.6 \times 4.3 \%$; $\mathrm{p}=0.587)$

\section{Discussion}

The prevalence of persistent ascites after DDLT has been found by other authors to vary from $3.4 \%$ to $7 \%$ [1-3]. That is significantly smaller than that found in studies evaluating living donor liver transplantation [LDLT; 11-15] which are largely accounted for by small for size grafts. We have found a greater percentage of this complication during the study period, which happened right after the change from chronological to gravity criteria. In roughly $50 \%$ of the sample, patients were decompensated and/or suffered some degree of renal failure. Another possible explanation for a greater rate of persistent ascites is the use of marginal grafts due to donor shortage. Inferior quality grafts are associated with increased vascular resistance and decreased complacency, which are known to increase portal hypertension [10]. Ascitic fluid analysis in our patients revealed an increased serumalbumin gradient suggesting persistence of an increased portal venous gradient. Two patients had neutrascites and were empirically treated with antibiotics, but ascites was not overly purulent and cultures were negative.

Some of these previous studies were made before the era of MELD listing. Stewart et al. [2] found ascites in 3.4\% of patients after 90 days and $80 \%$ of these had persistent ascites after one year, with lower survival than controls in patients that were treated with TIPS. In their study, gravity of clinical manifestations before transplant, hepatitis $\mathrm{C}$ and cold ischemia time were related to ascites persistence. Cirera et al. (2000) [1] found persistence of ascites in 7\% of liver transplantations after a median of 77 days. Patients with persistent ascites after DDLT were at increased risk of spontaneous bacterial peritonitis, loss of renal function and prolonged hospitalization. Ascites was more common with the use of piggyback technique $(11.1 \% \times 3.2 \%)$ and in male receptors. Increased wedged hepatic venous gradients were found in the affected patients. The authors have modified their piggyback technique in order to use all three hepatic veins afterwards, and observed an improvement with the problem of persistent ascites. More recently, Gotthardt et al. (2013) [3] found ascites lasting for more than 4 weeks after DDLT in $4.8 \%$ of cases. The most common underlying reason $(70 \%)$ was bacterial or fungal peritonitis, followed by obstruction of liver vein outflow, decreased renal function, and obstruction of the portal vein. Associated variables were refractory 
ascites before DDLT, re-transplantation, anemia and leucopenia. The 1-year survival rate was $92.3 \%$ for controls vs. $75.8 \%$ for cases according to Kaplan-Meyer analysis $(\mathrm{p}<0.05)$.

In LDLT, small-for-size syndrome is associated with intractable ascites and can be treated with splenic artery ligation, splenectomy, or hemiportocaval shunt, to modulate portal inflow and to reduce flow in smaller grafts [12]. Some authors believe that an increased portal blood flow can also be the cause of refractory ascites after DDLT as well $[13,14,16]$. Troisi et al. (1999) [16] performed 10 splenectomies in liver transplant patients, 3 of which indicated for massive ascitic fluid loss, based on the principle of reducing liver congestion due to excessive portal flow. However, 4 patients had sepsis with a fatal outcome. Kim et al. (2012) [14] and Pravisani et al. (2016) [13] managed to avoid major complications performing splenic artery embolization's in more than 30 patients and they achieved a marked reduction in ascitic volume. Although partial splenectomy or splenic artery embolization can minimize the risk of sepsis, we did not find an increased spleen size in our patients with persistent ascites, compared to those without, that could justify such invasive procedures.

It has been shown by some authors that ACR was correlated with an increased pressure gradient that increased progressively from mild to severe rejection and was shown to improve after treatment $[7,8]$. At the time of those early studies, however, immunosuppression was based on cyclosporine, prednisone and azathioprine and most cases of ACR were moderate or severe. This was rarely seen in our casuistic.

Some cases of ascites have been ascribed to veno-occlusive disease related to azathioprine use [11], but this drug is rarely used nowadays in DDLT, except for cases with auto-immune hepatitis, be it de novo or a relapse, and none of our patients with persistent ascites have received it. Post-operatory ultrasonographic exams are also routinely performed and this vascular complication was not seen.

Our results are more in accordance with those of Wu et al (2018) [15] in whose study risk factors after multivariate analysis included creatinine levels greater than $1.5 \mathrm{mg} / \mathrm{dL}$, recipient spleen to graft ratio greater than 1.3 and more than $1 \mathrm{~L}$ of ascites drained at laparotomy.

It is clear that the studies published so far regarding posttransplantation ascites are very heterogeneous. It seems that persistent ascites can be related to post-sinusoidal causes such as outflow obstruction, hepatic causes possibly due to reduced liver complacency (moderate or severe ACR, hepatitis C) and pre-sinusoidal causes like increased portal flow, portal vein thrombosis or, more commonly, peritoneal infections. We postulate that persistent ascites is a heterogeneous condition, and persistently altered hemodynamic associated with post-transplantation renal dysfunction seems to be the predominant cause in our casuistic. We observed a greater prevalence of persistent ascites than other authors and this could be related to a favouring of decompensated cirrhosis and/or renal dysfunction in the MELD era. It became common practice in our group to leave an abdominal tube after transplantation, on patients with greater ascites volume, and to provide albumin reposition according to tube drainage. A prospective study intent on investigating potential causes would be required for a better understanding of this ill-defined complication.

\section{Acknowledgments}

To the Liver Transplantation Group (Eduardo Soares Schlindwein, Ian Leipnitz, Mario Henrique Mendes de Mattos Meine, Guillermo
Kiss, Juliano Martini, Ane Micheli Costabeber, Fernanda Karlinski Fernandes Sacco).

\section{References}

1. Cirera I, Navasa M, Rimola A, Garcia-Pagán JC, Grande L, et al. (2000) Ascites after liver transplantation. Liver Transplantation 6: 157-162.

2. Stewart CA, Wertheim J, Olthoff K, Furth EE, Brensinger C, et al. (2004) Ascites after liver transplantation-a mystery. Liver Transplantation 10: 654-60.

3. Gotthardt DN, Weiss KH, Rathenberg V, Schemmer P, Stremmel W, et al. (2013) Persistent ascites after liver transplantation: Etiology, treatment and impact on survival. Annals of Transplantation 18: 378-383.

4. Lerut JP, Goffette P, Molle G, Roggen FM, Puttemans T, et al. (1999) Transjugular intrahepatic portosystemic shunt after adult liver transplantation: experience in eight patients. Clinical Transplantation 68: 379-384.

5. Vasta F, Luca A, Miraglia R, Spada M, Gruttadauria S, et al. (2005) Transjugular intrahepatic portosystemic shunt in adult liver recipient with delayed graft function. Transplantation Proceedings 37: 2626-2628.

6. Navasa M, Feu F, Gárcia-Pagán JC, Jiménez W, Llach J, et al. (1993) Hemodynamic and humoral changes after liver transplantation in patients with cirrhosis. Hepatology 17: 355-360.

7. Gadano A, Hadengue A, Widmann JJ, Vachieri F, Moreau R (1995) Hemodynamics after orthotopic liver transplantation: Study of associated factors and long-term effects. Hepatology 22: 458-465.

8. Hadengue A, Lebrec D, Moreau R, Sogni P, Duran F, et al. (1993) Persistence of systemic and splanchnic hyperkinetic circulation in liver transplant patients. Hepatology 17: 175-178.

9. Sainz-Barriga M, Reyntjens K, Costa MG, Scudeller L, Rogiersa X, et al. (2010) Prospective evaluation of intraoperative hemodynamics in liver transplantation with whole, partial and DCD grafts. American J Transplantation 10: 1850-1860.

10. Demetris AJ, Batts KP, Dhillon AP, Ferrel L, Fung J, et al. (1997) Banff schema for grading liver allograft rejection: an international consensus document. Hepatology 25: 658-663.

11. Ben-Ari Z (2004) Ascites after Transplantation-A Mystery (letter to the editor). Liver Transplantation: 10: 1221.

12. Matsudaira S, Ishizaki Y, Yoshimoto J, Fujiwara N, Kawasaki S (2017) Risk factors for intractable ascites after adult-to-adult living donor liver transplantation using left lobe. Transplantation Direct 3: e138.

13. Pravisani R, Baccarani U, Adani G, Lorenzin D, Vit A, et al. (2016) Splenic Artery Syndrome as a Possible Cause of Late Onset Refractory Ascites After Liver Transplantation: Management With Proximal Splenic Artery Embolization. Transplantation Proceedings 48: 377-379.

14. Kim H, Suh KS, Jeon YM, Park MS, Choi Y, et al. (2012) Partial splenic artery embolization for thrombocytopenia and uncontrolled massive ascites after liver transplantation. Transplantation Proceedings 44: 755-756.

15. Wu YJ, Wang SH, Elsarawy AM, Chan YC, Chen CL, et al. (2018) Prediction of the development of persistent massive ascites after living donor liver transplantation using a perioperative risk score. Transplantation 102: e275-e281.

16. Troisi R, Hesse UJ, Decruyenaere J, Morelli MC, Palazzo U, et al. (1999) Functional, life-threatening disorders and splenectomy following liver transplantation. Clinical Transplantation 13: 380-388. 